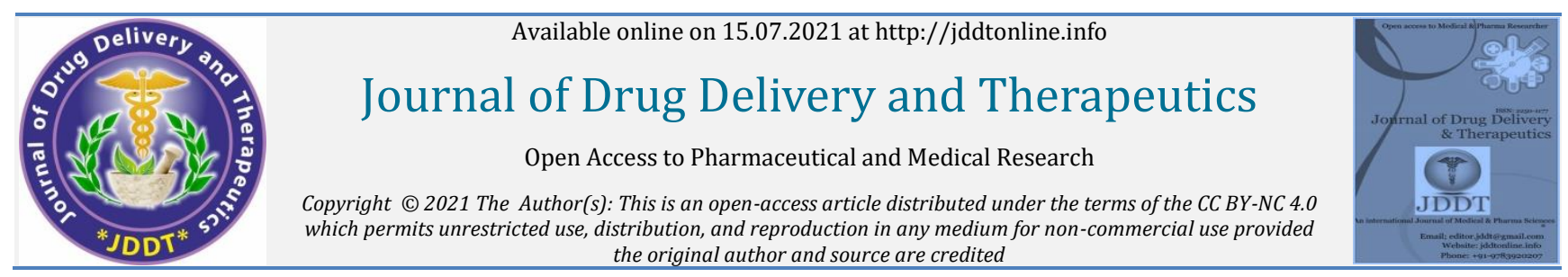

Open Access Full Text Article the original author and source are credited
tistion

Review Article

\title{
Topical Drug Delivery Therapeutics, Drug Absorption and Penetration Enhancement Techniques
}

\author{
(D)Kamal Singh Bani ${ }^{*}$, (D) Khushboo Bhardwaj² \\ 1. Department of Pharmaceutics, BBSIPAS College, Greater Noida, U.P., India \\ 2. Department of Pharmaceutics, Dr K.N. Modi Institute of Pharmaceutical Education and Research, Modinagar (Ghaziabad), U.P., India
}

\begin{abstract}
Article Info:

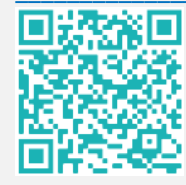

Article History:

Received 17 May 2021

Review Completed 24 June 2021

Accepted 29 June 2021

Available online 15 July 2021

*Address for Correspondence:

Mr. Kamal Singh Bani, Assistant Professor, Department of Pharmaceutics, BBSIPAS College, Greater Noida, U.P., India.

ORCID ID: https://orcid.org/0000-0001-7568-9912

\section{Cite this article as:}

Bani KS, Bhardwaj K, Topical Drug Delivery Therapeutics, Drug Absorption and Penetration Enhancement Techniques, Journal of Drug Delivery and Therapeutics. 2021; 11(4):105-110

DOI: http://dx.doi.org/10.22270/jddt.v11i4.4864

\section{Abstract}

The delivery of medications through the skin has long been a fascinating as well as difficult subject of study. For different medications, topical drug administration has brought substantial benefits over the systemic route, one of the most important of which is reduced toxicity due to minimal or no exposure to non-target organs. Because of its simplicity and affordability, topical administration is the preferred method for delivering medicinal substances locally. Topical drug delivery system includes solid powders, semisolids, liquid preparations, and sprays, among other pharmaceutical dose forms. Gels, creams, and ointments are the most often used semisolid preparations for topical medication delivery. Topical medication delivery methods allow a medicine to enter the systemic circulation at a controlled rate by penetrating the epidermal layer. New drugs are being developed utilizing the transdermal approach in addition to the existing formulations due to the inherent benefits of delivery via this route. Although low skin permeability limits its applicability, it does provide a non-invasive route of medication administration. Innovative research using penetration-enhancing technologies such iontophoresis, electroporation, microneedles, sonophoresis, and others offers promise for successful implementation of these drugs in clinical practice as consumer-friendly, transdermal dosage forms. This paper examines some of the most promising new strategies for enhancing transdermal permeability, as well as providing a scientific update on recent improvements in the topical drug delivery system. The current study focuses on the most modern methods and techniques for administering local treatment to the skin. This data can be used as a foundation for further research and development of existing methodologies and technologies.
\end{abstract}

Keywords: Topical drug delivery, Recent techniques, TDDS, Advances in skin delivery

\section{INTRODUCTION}

The administration of a pharmaceutical dosage form to the skin for the treatment of a cutaneous condition or a cutaneous manifestation of a general disease with the purpose of confining the drug's pharmacological or other activity to the skin's surface is known as topical delivery. The skin is one of the most easily accessible routes for drug delivery, and topical drug delivery systems are one of the most common. Chemicals entering into and through the skin are assumed to pass through the stratum corneum, which has long been thought to be the most critical barrier. The presence of stratum corneum on the surface, on the other hand, makes it selective towards previously delivered drugs or delivery methods.

Humans have long been troubled by diseases and ailments of the body and mind. On the other hand, dedicated research by scientists all over the world has made it possible to treat, prevent, and remove many of humanity's ailments. Pharmaceutical research has advanced steadily throughout time, and it is now essential to keeping people well and preventing disease. The use of biomolecules such as medications, proteins, and other biomolecules to cure diseases has advanced dramatically in recent decades. They could only be employed in a limited way at first due to the limitations of drug delivery via hazardous circumstances in the body. ${ }^{1-3}$

Some of the major benefits provided by topical drug delivery include improved bioavailability, more uniform plasma levels, longer duration of action resulting in a reduction in dosing frequency, reduced side effects, and improved therapy due to the maintenance of plasma levels up to the end of the dosing interval compared to a decline in plasma levels with conventional oral dosage forms.

The primary advantage of adopting a topical administration method is that it bypasses first-pass metabolism. Another benefit of topical formulations is that they avoid the risks and drawbacks of intravenous therapy, as well as the numerous conditions that affect absorption, such as $\mathrm{pH}$ variations, enzyme presence, and gastric emptying time. Topical distribution is dominated by semi-solid formulations in all its forms, but foams, sprays, medicated powders, solutions, and even medicated adhesive systems are also 
used. When other means of medication administration fail, the topical drug delivery system is used to treat pain, contraception, and urinary incontinence. In recent decades, drugs have been administered to the human body through a variety of channels, including oral, sublingual, rectal, parental, topical, inhalation, and others.

Externally used topicals and internally used topicals for local activity are the two types of topical medicine delivery systems. Topical drug delivery methods provide a number of advantages, including avoiding first-pass metabolism, avoiding gastrointestinal incompatibilities, improving patient compliance, self-medication, and drugs having a limited shelf life. It's self-evident that you can get through the skin barrier. The topical drug delivery system is affected by physiological factors such as skin thickness, hydration, inflammation, and $\mathrm{pH}$, lipid content, densities of hair follicles and sweat glands, blood flow, and physicochemical factors such as partition coefficient, molecular weight, and degree of ionization.

The application of a drug-containing formulation to the skin to treat cutaneous disorders (e.g., acne) or cutaneous manifestations of a general disease (e.g. psoriasis) with the goal of limiting the drug's pharmacological or other effect to the skin's surface or within the skin is referred to as topical drug delivery. Topical action may or may not require intracutaneous injections. ${ }^{4,5}$ Pharmaceutical dosage forms utilized in topical drug delivery systems include semisolids, liquid preparations, sprays, and solid powders. The most commonly used semisolid formulations for topical medicine administration are gels, creams, and ointments. 6

Topical therapies function by affecting the afflicted region directly. A gel is a cross-linked two-component, threedimensional network of structural elements. The structural ingredients that make up the gel network can be inorganic particles or organic macromolecules, such as polymers. ${ }^{7}$

Topical delivery includes two basic types of products, i.e., internal and external topicals. Internal topicals with local activity that are applied orally, vaginally, or on anorectal tissues to the mucous membrane. External topicals are sprayed, sprayed, or otherwise spread on the cutaneous tissues to cover the affected area. Due of pharmaceutical penetration into the underlying tissue, topical therapies are most commonly used for localized effects at the application point. Although some medication may be absorbed inadvertently, it is normally in small amounts and has minimal impact. 8,9

\section{ANATOMY AND PHYSIOLOGY OF SKIN:}

Human skin is made up of three tissues: the stratified, vascular, cellular "epidermis," the underlying dermis of connective tissues, and the hypodermis. 10
A microscopic section of the epidermis reveals the stratum corneum, stratum lucidum, stratum granulosum, stratum spinosum, and stratum germinativum.

The human body has two systems that protect it from harmful organisms found in the environment. The internal defence system destroys microorganisms and germs that have already infiltrated the body. Microbial germs are kept out by the body's external defence mechanism. The skin is the largest external defence mechanism. Skin not only protects the outside of the body, but it also serves additional purposes. The skin is the largest external defence mechanism. Skin not only protects the outside of the body, but it also serves additional purposes. It serves as a mechanical barrier between the inner workings of the body and the outside environment. ${ }^{11}$ Depending on the environment, the skin temperature varies between $30^{\circ} \mathrm{C}$ and $40^{\circ} \mathrm{C} .12$

\section{Epidermis:}

The absence of blood vessels is the epidermis' most distinguishing feature. The capillaries of the dermis give nutrients. The epidermis, or top layer of skin, is a stratified, squamous, keratinizing epithelium. Keratinocytes, which are responsible for the skin's barrier properties, account for more than $90 \%$ of the total. 13

\section{Dermis:}

The next layer of the dermis skin is a thick layer of fibrous and elastic tissue that gives it flexibility and strength. This layer is primarily composed of collagen, elastin, and fibrillin. The dermis contains nerve endings, sweat glands, oil glands, hair follicles, and blood vessels. ${ }^{14}$ The dermis is a vascularized collagen-rich connective tissue that contains mucopolysaccharides (also known as the ground material). ${ }^{15}$

\section{Hypodermis:}

The hypodermis is the deepest layer of the skin. It is the layer that connects the body's underlying tissues, such as muscles and bone, to the skin. Although they are coated in the epidermis, sweat glands, sebaceous glands, and hair follicles all have their origins in the dermis. On the skin's surface, sweat glands release a dilute salt solution. The skin is cooled by the evaporation of this mild salt solution, which is important for body and skin temperature regulation. Sweet glands are present all over the body. Below fig. 1 shows the anatomy of skin. The temperature of the environment, the quantity of heat-generating skeletal muscle activity, and a range of emotional factors all influence the number of dilutions (sweet) produced. Hair follicles secrete sebum, an oily liquid that is then deposited on the skin's surface. Sebum is a water-resistant layer that keeps hair and skin from drying out. 16 


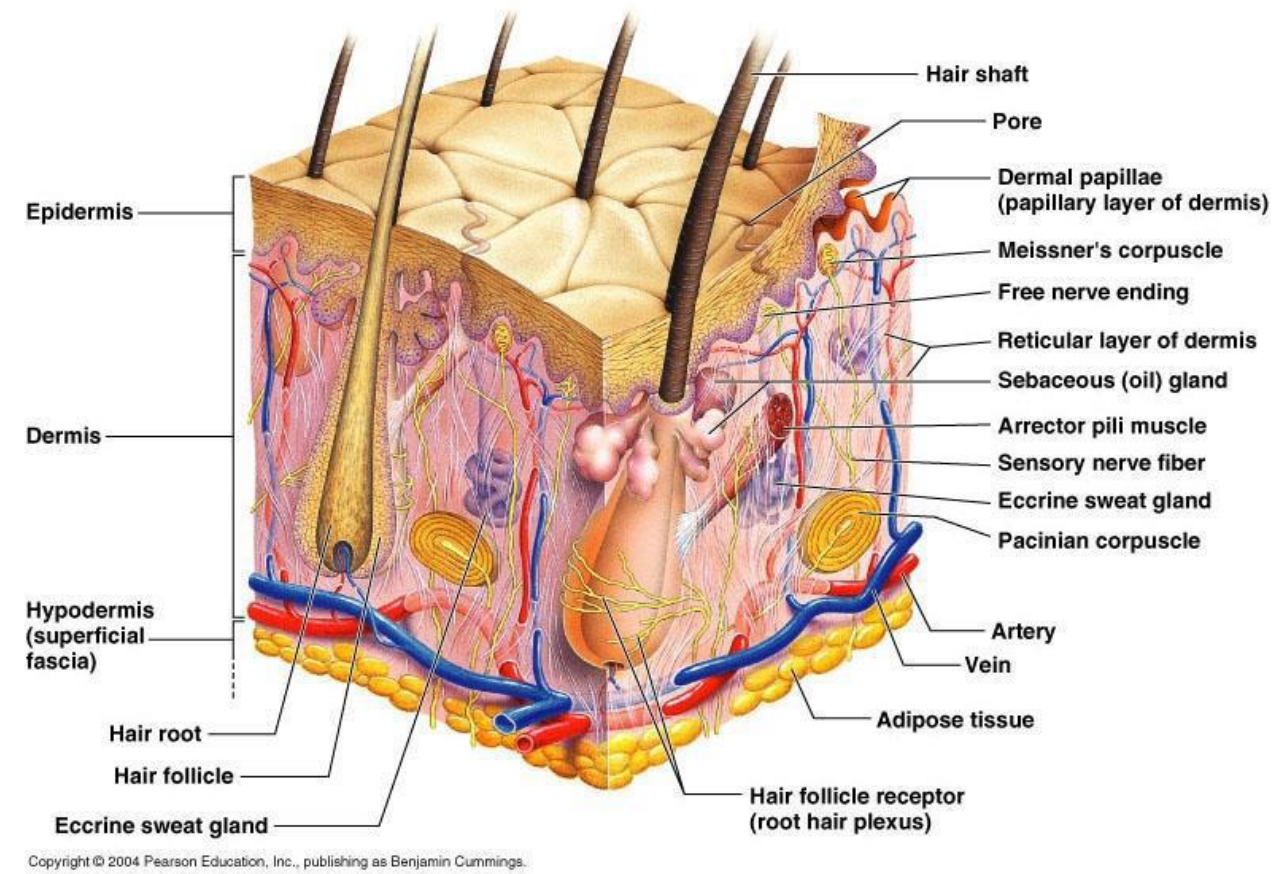

Copyright ( 2004 Pearson Education, Inc., publishing as Benjamin Cummings Human Anatomy \& Physiology, Sixth Edition Elaine N. Marieb PowerPoint ${ }^{\circledR}$ Lecture. - ppt download (google.com)

Figure 1: Anatomy of Skin 37

\section{CLASSIFICATION OF TOPICAL DRUG DELIVERY SYSTEMS:}

1. Solid preparation: Topical Powders, Plasters Ointments, poultices.

2. Semi solid preparation: Creams, Poultices, Gels, Pastes, ointment.

3. Liquid preparation: Liniment, Lotions, solution, tinctures, Emulsions, Suspensions, Paints.

4. Miscellaneous preparation: Transdermal drug delivery systems, Tapes and Gauzes, Rubbing alcohols, Liquid cleanser, and Topical aerosol.

\section{FACTORS AFFECTING TOPICAL ABSORPTION OF DRUGS:}

Physiological and physicochemical considerations are taken into account for drug absorption in topical areas.

\section{Physiological factors:}

1. Thickness of skin.

2. Lipid content.

3. Density of hair follicles.

4. Density of sweat glands.

5. $\mathrm{pH}$ of skin.

6. Blood flow.

7. Skin hydration.

8. Inflammation of skin.

\section{Physicochemical factors:}

1. Partition coefficient.

2. Molecular weight ( $<400$ Dalton)

3. Degree of ionization
4. Effect of vehicles. ${ }^{17}$

\section{FACTORS TO BE CONSIDERED WHILE CHOOSING A TOPICAL PREPARATION:}

1. Potential for enragement or sensitization in general, ointments and creams with water and oils are less irritating, whereas gels irritate. If you have an allergy to preservatives or emulsifiers, ointments are not for you. 18

2. The type of preparation should correspond to the type of lesions.

3. Match the kind of preparation to the location. (For example, for hairy places, a gel or lotion) 19

\section{Advantages:}

- Using d/o/w emulsions, hydrophobic medicines can be easily integrated into gels.

- Increased stability.

- There will be no intensive sonication.

- Stay away from first-pass metabolism.

- More focused on a single location.

- Stay away from foods that are incompatible with your gastrointestinal system.

- Increasing the patient's willingness to comply.

- Self-medication is possible.

- Ensuring that a medicine with a short biological half-life and a restricted therapeutic window is used.

- The ability to easily stop taking medication.

- Provide medicine distribution that is specific to the patient's needs.

- Simple to make and inexpensive to prepare.

- Increased loading capacity 
- Release is regulated.

- Convenient and simple to use. 20

\section{Disadvantages:}

- Excessive irritability of the skin

- The risk of an allergic response.
- Some drugs have a low permeability through the skin.

- Large-particle drugs are difficult to absorb via the skin.

- Contact dermatitis causes skin inflammation.

- The occurrence of a bubble during emulgel formulation. $21,22,23$

Table 1: Novel Carriers for topical delivery ${ }^{24}$

\begin{tabular}{|c|c|c|}
\hline S.NO. & Carriers & Application \\
\hline 1. & $\begin{array}{l}\text { Transferosomes } \\
\text { (elastic liposomes) }\end{array}$ & $\begin{array}{l}\text { It is a modified lipid-based soft, flexible carrier designed for improved systemic drug } \\
\text { administration. It can be used for noninvasive medication delivery into or across the deeper } \\
\text { layers of the epidermis and/or the systemic circulation. }\end{array}$ \\
\hline 2. & Archaeosomes & $\begin{array}{l}\text { Archaeosomes are vesicles made up of Archaea glycerolipids that have high adjuvant activity and } \\
\text { can be used for molecular shielding and particular targeting. }\end{array}$ \\
\hline 3. & Aquasomes & $\begin{array}{l}\text { Aquasomes are three-layered self-assembly compositions with a ceramic nanocrystalline } \\
\text { particle core and a glassy layer of polyhydroxy chemicals that have potent adjuvant effect. }\end{array}$ \\
\hline 4. & Discomes & $\begin{array}{l}\text { The dicomes are niosomes that have been solubilized in a nonionic surfactant solution } \\
\text { (polyoxyethylene cetyl ether glass) for use in ligand-mediated drug targeting. }\end{array}$ \\
\hline 5. & Emulsomes & $\begin{array}{l}\text { Emulsomes are nanosized lipid particles (bioadhesive nanoemulsions) made up of tiny lipid } \\
\text { assemblies with a polar core that are used in the parenteral administration of medications that } \\
\text { are poorly water soluble. }\end{array}$ \\
\hline 6. & Cryptosomes & $\begin{array}{l}\text { Cryptosomes are lipid vesicles with a surface coat made of PC and a polyoxyethylene derivative } \\
\text { of phosphateidylethanolamine that can be used to target drugs using ligands. }\end{array}$ \\
\hline 7. & Enzymosomes & $\begin{array}{l}\text { Enzymosomes are liposomes that are meant to generate a micro bioenvironment in which } \\
\text { enzymes are covalently fixed or linked to the liposomes' surface and are used to deliver drugs to } \\
\text { tumour cells. }\end{array}$ \\
\hline 8. & Ethosomes & $\begin{array}{l}\text { Ethosomes are lipid-based soft, flexible vesicles that include a permeation enhancer and are } \\
\text { made up of phospholipids, ethanol, and water. They're used to deliver drugs to deep skin layers. }\end{array}$ \\
\hline 9. & Genosomes & $\begin{array}{l}\text { Genosomes are artificial macromolecular complexes that facilitate the transmission of functional } \\
\text { genes. Cationic lipids are ideal because of their high biodegradability and systemic stability, as } \\
\text { well as their usage in cell-specific gene transfer. }\end{array}$ \\
\hline 10. & Photosomes & $\begin{array}{l}\text { Photosomes are photolyases encapsulated in liposomes that release their contents as a result of } \\
\text { photo-triggered changes in membrane permeability. They are used in photodynamic therapy. }\end{array}$ \\
\hline 11. & Vesosomes & $\begin{array}{l}\text { It is the "interdigitated" bilayer phase created by adding ethanol to a variety of saturated } \\
\text { phospholipids suited to nested-bilayer compartments. The internal components of serum are } \\
\text { better protected by the many compartments of vesosomes. }\end{array}$ \\
\hline 12. & Novasomes & $\begin{array}{l}\text { It's made up of glyceryl dilaurate, cholesterol, and polyoxyethylene } 10 \text {-stearyl ether in a weight- } \\
\text { to-percentage ratio of } 57: 15: 28 \text {, and it's used to deliver drugs to the pilosebaceous compartment. }\end{array}$ \\
\hline 13. & Proteosomes & $\begin{array}{l}\text { Proteosomes are high-molecular-weight multi-subunit enzyme complexes with catalytic activity } \\
\text { that is primarily attributable to the assembly pattern of enzymes that allows for greater catalytic } \\
\text { activity turnover than non-associated enzymes. They can be used as an adjuvant as well as a } \\
\text { protein carrier. }\end{array}$ \\
\hline 14. & Virosomes & $\begin{array}{l}\text { Its virus-spiked liposomes that have been integrated into liposome bilayers based on retrovirus- } \\
\text { derived lipids and used as immunological adjuvants. }\end{array}$ \\
\hline
\end{tabular}

\section{DIFFERENT METHOD TO ENHANCE DRUG PENETRATION AND ABSORPTION:}

Recent advancements in these technologies have resulted from breakthroughs in precision engineering (bioengineering), computing, chemical engineering, and material sciences, resulting in the development of devices enabling drug administration to the skin to accomplish the desired therapeutic effect. ${ }^{23}$ The active methods or devices for topical medication administration are listed below:

\section{Iontophoresis:}

Iontophoresis is the application of electric current to enhance the absorption of topically administered medicinal substances through the skin. An electrode with the same charge as the drug is used to apply the drug, while an indifferent counter electrode is placed elsewhere on the body. The active electrode successfully repels and drives the active material into the skin. 25,26 


\section{Ultrasound (Sonophoresis or Phonophoresis):}

Ultrasound, also known as sonophoresis or phonophoresis, is the application of ultrasonic energy to increase the transdermal transport of solutes either concurrently or via pre-treatment. The creation of gaseous cavities within the intercellular lipids in response to ultrasonic exposure, resulting in disruption of the skin's subcutaneous layer, is thought to be the mechanism behind the increase in skin permeability. The ultrasound, also known as sonophoresis, is a method of increasing the absorption of topical substances (transdermal administration) into the epidermis, dermis, and subcutaneous tissues. Ultrasound waves create microvibrations inside the skin epidermis, increasing the overall kinetic energy of molecules in topical treatments, resulting in sonophoresis. In hospitals, it is commonly used to give medications through the skin. ${ }^{27}$

\section{Laser radiation and photomechanical waves:}

Ultrasound waves create micro-vibrations inside the skin epidermis, increasing the overall kinetic energy of molecules in topical treatments, resulting in sonophoresis. In hospitals, it is commonly used to give medications through the skin. The SC is ablation without severe harm to the underlying epidermis when the skin is exposed to laser energy in this manner. The removal of the skin's subcutaneous layer has been proven to improve the administration of lipophilic and hydrophilic medicines 28

\section{Electroporation:}

Electroporation is a technique for delivering medications or genes into cells that involves delivering short, powerful electric pulses that transiently permeabilize the cell membrane, allowing molecules that would otherwise be unable to pass through it to enter the cell. When the molecules to be transported are chemotherapeutic agents, this process is known as electro-chemotherapy, and when the molecules to be transported are DNA, it is known as gene electro transfer. ${ }^{29}$

\section{Radio-frequency:}

It entails exposing skin to a high-frequency alternating current of $100 \mathrm{kHz}$, which exposes the production of heatinduced micro channels in the skin's membrane, similar to what happens when laser radiation is used. The number and depth of the micro channels generated by the device, which is dependent on the qualities of the microelectrodes utilised in the device, regulate the rate of drug delivery. 30

\section{Magnetophoresis:}

Magnetophoresis is a process in which a magnetic field is used to enhance medication absorption through biological barriers. Magnetophoresis has been proven to improve transdermal medication delivery in both in vitro and in vivo experiments 31 Magnetokinesis and increased drug partitioning into the stratum corneum were discovered to be the most common mechanisms for improving drug penetration.

\section{Microporation:}

Microporation is a procedure in which microneedles are inserted into the skin and puncture only the stratum corneum, increasing skin permeability. Microneedles are needles with a length of 10 to 200 metres and a width of 10 to 50 meters 32

\section{Use of permeation enhancers:}

The incorporation of penetration enhancers improves medication absorption by changing the stratum corneum's barrier property. It should be pharmacologically inert, nontoxic, nonirritating, nonallergic, odourless, tasteless, colourless, compatible with most drugs and excipients, affordable, and with good solvent characteristics.

Over the last two decades, a variety of penetration enhancers have been developed, including alcohols and polyols (ethanol, propylene glycol), surfactants (Tween, Span, SLS), fatty acids (oleic acid), amines and amides (Azone, Nmethylpyrrolidone), terpenes (limonene), sulfoxides (dimethylsulfoxide), and esters (isopropylmyristate). 33,34,35

\section{Prodrug Approach:}

Therapeutically inactive compounds of therapeutically active medicines are known as prodrugs. The metabolism of a prodrug results in the production of the therapeutically active drug. A prodrug differs from the parent drug in terms of lipophilicity and physicochemical characteristics. 36

\section{CONCLUSION}

The current review reveals that topical medication administration is a relatively new approach. We can easily access different medications into the skin by using topical formulations. as a result of the many approaches utilized to improve absorption through the skin membrane The topical drug delivery system is primarily utilized in the treatment of skin conditions. In that case, the topical formulation has a local contact effect on the skin illness and can be used to treat mild to severe skin disorders. Small dispersed medication particles can be used to create a variety of topical gel compositions. Patient considerations such as dose form efficacy and ease of use are crucial.

\section{REFERENCES}

1. Sarkhejiya, NA, Baldaniya LH, Hydrogels: A versatile drug delivery carrier systems, Int journal of Phr Sci and Nanotechnology, 2012; 5(3):1745-1756.

https://doi.org/10.37285/ijpsn.2012.5.3.1

2. Gupta AK, Environmental Responsive Hydrogels: A Novel Approach in Drug Delivery System, Journal of Drug Delivery and Therapeutics, 2012; 2(1):81-88. https://doi.org/10.22270/jddt.v2i1.87

3. Chourasia MK, Jain SK, Pharmaceutical approaches to colon targeted drug delivery systems, Journal of Pharmaceutical sciences, 2012; 6(1):33-66.

4. Bioequivalence, and Penetration, 1, Springer, USA, 1993, 369-391.

5. Kaur J, Singh G, Saini S, Aspects Related To the Solid Lipid Nanoparticles Delivery through the Topical Route, Journal of Drug Delivery and Therapeutics, 2012; 2(6):111-116 https://doi.org/10.22270/jddt.v2i6.309

6. Gisby J, Bryant J, Efficacy of a new cream formulation of mupirocin: Comparison with oral and topical agents in Experimental skin infections, Antimicrobial agents and chemotherapy, 2000; 44(2):255- 260. https://doi.org/10.1128/AAC.44.2.255-260.2000

7. Mazher Ahmed and Musharraf Ali. Semisolid Dosage Form: Topical Gel Formulation A Review. World J P'ceutical Rese2016; 5(12):1256-1268.

8. Kaur J, Kaur J, Jaiswal S, Gupta GD. Recent Advances In Topical Drug Delivery System.Indo American P'ceutical Re, 2016; 6(7):2231-6876

9. Chittodiya P, Tomar RS, Ramchandani U, Manocha N, Agrawal .Topical Gel - A Review, Int. J P'ceutical\& Biological Archives .2013; 4(4):606 - 613.

10. Narasimhulu A, Tzammulferdous S, M. Niranjan Babu.A Review onTransdermal Drug Delivery System. Asian J Res in Biological and P'ceutical Scie. 2015; 2:59 - 65. 
11. Sherwood L, Human Physiology: From cells to systems, 6, Thomson Brooks, Stamford, 2007.

12. Noble WC, The skin microflora and microbial skin disease, University of Cambridge, Cambridge.

13. Asija R, Asija S, Sharma D, Dhakar PC, Nama N: Topical ointment: an updated review. Drug Discovery T'peutics. 2015; 3(25):4751.

14. Verma A, Singh S, Kaur R, Jain UK.Topical gel as Drug Delivery System: A Review. Int. J. Pharm. Sci. Rev. Res 2013; 23(2):374382.

15. Chandel A, Parashar B, Gupta N, Kumar A, SharmaV.An Overview On The Gel Formulation. Int Journal Pharm Rev Rese2013; 2(1):18-22.

16. Sowmya J, Gowda DV, Srivastava A.Topical Gels: A Recent Approach for Novel Drug Delivery.Int.J Health Scie and Rese2015; 5(10):305-312.

17. Jain Singh RP, Parpani S, Narke S, Chavan R. Emulgel: A Recent Approach For Topical Drug Delivery System. AJPRD, 2014; 22:112-231

18. Kuller R, Saini S, Seth N, Rana AC, Emulgel: A surrogate approach for topical used hydrophobic drugs. Int J Pharm Bio Sci., 2011; 1(3):117-128.

19. Ajazuddin, Alexander A, Khichariya A, Gupta S, Patel RJ, Giri TK et al. Recent expansions in an emergent novel drug delivery technology: Emulgel. J Control Release, 2013; 171:122-32. https://doi.org/10.1016/j.jconrel.2013.06.030

20. Murty SN, Hiremath SRR.Physical and chemical enhancer in transdermal delivery of terbutaline sulphate.AAPS Pharm Science Technology, 2001; 2:1-5 https://doi.org/10.1208/pt0201_tn1

21. Ojha NK, Kumar A. HPTLC profile of aqueous extract of different chromatographic fractions of Aloe barbadensis Miller, Asian Pac J Trop Dis, 2012; 104-843 https://doi.org/10.1016/S22221808(12)60133-9

22. Murty SN, Hiremath SRR.Physical and chemical enhancer in transdermal delivery of terbutaline sulphate.AAPS Pharm Science Technology, 2001; 2:1-5 https://doi.org/10.1208/pt0201_tn1

23. Hardenia A, Jayronia S, Jain S. Emulgel: An emergent tool in topical drug delivery. International journal of pharmaceutical sciences and research. 2014; 5(5):1653.

24. Marakanam S. Umashankar, Rajesh K. Sachdeva, Monica Gulati Aquasomes: a promising carrier for peptides and protein delivery, Nanomedicine: Nanotechnology, Biology, and Medicine 2010; 6:419-426 https://doi.org/10.1016/j.nano.2009.11.002
25. Reena R, Srinivas CR. Iontophoresis in Dermatology. Indian Dermatol Venereol Leprol 2005; 71(4):236-41. https://doi.org/10.4103/0378-6323.16613

26. Preat V, Vanbever R. Skin Electroporation for Transdermal and Topical Drug Delivery. In: Guy RH, Hadgraft J, editors. Transdermal Drug Delivery. 2nd ed. New York: Marcel Dekker; 2003. p. 227-54 https://doi.org/10.1201/9780203909683-6

27. Brown MB, Traynor MJ, Martin GP, Akomeah FK. Transdermal drug delivery systems: skin perturbation devices. Methods Mol Biol. 2008; 437:119-39. https://doi.org/10.1007/978-1-59745210-6_5

28. Jacques, S.L., McAuliffe, D.J., Blank, I.H. and Parrish, J.A. (1988) "Controlled removal of human stratum corneum by pulsed laser to enhance percutaneous transport", Patent Serial Number US 4, 775,361 .

29. Sarah Yang (2007-02-12). "New medical technique punches holes in cells, could treat tumors". Retrieved 2007-12-13.

30. Brown MB, Traynor MJ, Martin GP, Akomeah FK. Transdermal drug delivery systems: skin perturbation devices. Methods Mol Biol. 2008; 437:119-39. https://doi.org/10.1007/978-1-59745 210-6_5

31. Huczko A, Lange H. Fullerenes: experimental evidence for a null risk of skin irritation and allergy. Fullerene Sci Technol 1999; 7:935-9. https://doi.org/10.1080/10641229909351390

32. Rai R, Srinivas CR. Iontophoresis in dermatology. Indian J Dermatol Venereol Leprol 2005; 71:236-41 https://doi.org/10.4103/0378-6323.16613

33. Jacques, S.L., McAuliffe, D.J., Blank, I.H. and Parrish, J.A. (1988) "Controlled removal of human stratum corneum by pulsed laser to enhance percutaneous transport", Patent Serial Number US 4, $775,361$.

34. Murthy SN, Sammeta SM, Bowers C. Magnetophoresis for enhancing transdermal drug delivery: Mechanistic studies and patch design. J Control Release, 2010; 148:197-203. https://doi.org/10.1016/j.jconrel.2010.08.015

35. Zerweck C, Grove G, Fraser JM. Moisturization potential of two acne gels containing $5 \%$ benzoyl peroxide and $1 \%$ clindamycin Presented at: AAD Summer Academy Meeting, July 26-30, 2006 San Diego, CA; P100

36. Daniels R. Strategies for Skin Penetration Enhancement. Skin Care Forum. 2004. Issue 37.

37. Copyright (C) 2004 Pearson Education, Inc., publishing as Benjamin Cummings Human Anatomy \& Physiology, Sixth

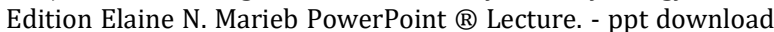
(google.com) 